\title{
False memories: finding a balance
}

\author{
Phil Mollon
}

There can be few more agonising experiences than being falsely accused of having sexually abused one's child - except perhaps to be told that one's long-standing memories of childhood abuse are an example of false memory syndrome. People have been profoundly hurt both by false accusations of abuse and by false denials and dismissals of memories of abuse. Both of these can happen.

\section{Where we can all agree}

It is quite possible to write either an article which supports the position of false memory advocates, or one which gives credence to recovered memories, depending on what evidence one chooses to select. Because of the extraordinary dominance of false memory rhetoric in media coverage of this subject, I will attempt to redress the balance by urging some caution and pointing to ways in which current arguments and assumptions can mislead.

Most informed commentators would probably agree on the following points. Memory does not access an exact copy of an experience, like a videorecording or a computer file. Instead, remembering is an active process of reconstructing, which introduces distortion; however, memory for central features of an event is often accurate. Recollections can be influenced by suggestion, from both internal and external sources. The distorting effect of suggestion can be enhanced if the suggestion is repeated, if the person giving the suggestion is perceived to have authority, and if there is an attempt to remember events that happened a long time ago. Memory may be influenced by psychodynamic factors as well as by cognitive limitations. The experimental evidence for the creation of completely false memories is considerably less than that for the distortion of memories of actual events (British Psychological Society, 1995; Mollon, 1998).

\section{Distortion and polarisation}

The problem for the unwary reader, wishing to be informed about good practice in relation to memory of childhood, is that the current debate is pervaded by polemics, distortion and polarisation. As Brown et al (1998) comment:

"From the very beginning, the debate has been characterised by a viciousness unparalleled in the annals of contemporary scientific disagreements. Because of the zealotry, science has taken a back seat. In its place have been wild and inaccurate articulations or 'hyperbole' and 'rhetorical devices'...that have served, not as science, but as emotional sound bites for a gullible media."

What impairs our capacity to think about this subject? There may be a number of factors, but I will note just two which may be relevant. First, the issues are immensely complex, defying easy and clear resolution; this complexity and ambiguity can be highly aversive and tends to drive people towards a quasi-delusional clarity. Second, there can be discerned a movement between two polar extremes; covering over and minimisation of the prevalence and nature of childhood sexual abuse, countered by an exaggeration of sexual abuse. It is as if in our collective shock at the revelations of sexual abuse of children, which assault our awareness almost daily in news reports, we oscillate between excessive preoccupation and denial. This is analogous to the biphasic post-traumatic stress responses of 'numbing' and denial and being overwhelmed with intrusive thoughts.

Phil Mollon is a psychoanalytic psychotherapist and a clinical psychologist. He works as an adult psychotherapist and is Head of Clinical Psychology Services at Lister Hospital, Coreys Mill Lane, Stevenage, Hertfordshire SG1 4AB. He was a member of the British Psychological Society Working Party on Recovered Memories and has recently written a book on this subject. 
Incorrect beliefs about the reliability of memory, or about a necessary link between an adult psychological difficulty and a childhood trauma, can certainly be harmful. The problem is that in rightly cautioning against inappropriate assumptions and therapeutic practices, some of those who are aligned to the false memory societies are in danger of 'throwing the baby out with the bathwater' and dismissing the genuine traumatic experiences of many patients. By giving exaggerated emphasis to unlikely and extremely rare recovered memories, such as those of alien abductions, the more ordinary recollections of childhood trauma become discredited. This too can be harmful. A patient is reported to have committed suicide after being told by a psychiatrist that her memories of abuse by her father were an instance of false memory syndrome; her mother corroborated her account (Sunday Independent, 5 April 1998). A study of 113 surviors of childhood sexual abuse in Ottawa found that exposure to false memory rhetoric led to an increase in symptoms of anxiety and depression (Brownet al, 1998).

Advocates of false memory syndrome sometimes claim that childhood history should not be explored, on the grounds that doing so conveys an implicit suggestion that childhood trauma is responsible for the adult psychiatric condition. For example, Kihlstrom (1996), referring to the "cultural context ...increasingly permeated by unwarranted beliefs about the prevalence of abuse...", argues: "Within this socio-cultural milieu, even a few probing questions and suggestive remarks by an authority figure such as a therapist may be sufficient to inculcate a belief on the part of a patient that he or she was abused, and start the patient on the road towards the 'recovery' of false memories". This view would appear to attribute remarkable suggestibility to psychiatric patients. Astonishingly, Kihlstrom further remarks, "there is nothing in the available evidence that would permit us to have any confidence...that there are causal links between trauma, amnesia and psychopathology". By implication, enquiring about a patient's childhood is malpractice!

Distortion is inherent in some of the language which permeates the debate. Terms such as 'false memory syndrome', 'recovered memory therapy' and 'robust repression' are invented by those allied to the false memory societies and have questionable validity (Hovdestad \& Kristiansen, 1996). Despite being described as: "a useless trendy therapy from the United States" (Sidney Brandon quoted in The Guardian, 1 April 1998), there is no recognised school or method of recovered memory therapy. Indeed, to call somebody a 'recovered memory therapist', with its connotations of poor training, unscientific beliefs, and eccentric malpractice, is likely to be both insulting and libellous. Having framed the debate in those terms, some commentators then falsely attribute certain beliefs and clinical practices to those whose views may differ from their own. For example, a member of the Royal College of Psychiatrists' Working Group on Reported Recovered Memories of Child Sexual Abuse, who dissented from the majority report, was alleged, quite incorrectly to: "favour hypnosis and other memory enhancement techniques to bring back the alleged abuse" (Sunday Times, 29 March 1998); thus, a respected consultant psychotherapist was branded a recovered memory therapist!

The use of a noun ('a memory') to describe a process may itself mislead, giving rise to a reified notion of memory, as if it were a computer file, to which access can be blocked. This then leads to the assumption that a memory is either right or wrong - like a clean or corrupted computer file - and further, to the assumption that if it is corrupted, then someone must have infected it with a therapeutic 'virus'. The pioneer of memory studies, Frederic Bartlett, commented:

"If there be one thing upon which I have insisted more than another...it is that the description of memories as 'fixed and lifeless' is merely an unpleasant fiction...Our studies have shown us that all manner of changes in detail constantly occur in instances which every normal person would admit to be genuine instances of remembering" (Bartlett, 1995).

Remembering is essentially thinking about a past experience. If we avoid thinking about the experience (because it evokes anxiety) then we do not remember it. There is no implausible 'mechanism' involved.

\section{Evidence for forgetting}

It is commonly asserted that there is no evidence for motivated forgetting of trauma. For example, Brandon et al (1998), with typical reification of memory, state:

"Despite widespread clinical support and popular belief that memories can be 'blocked out' by the mind, no empirical evidence exists to support either repression or dissociation."

There are at least 30 studies demonstrating forgetting in response to childhood trauma (Brown et al, 1998). These studies tend to be criticised on grounds such as: in some instances the abuse may have occurred at such an early age that conscious memory would not be expected; the reports of abuse may be false, resulting from suggestion by biased therapists; the apparent 'repression' may simply be 
due to the respondent not wishing to speak of the abuse; or the results may reflect 'ordinary forgetting' (Loftus et al, 1994; Pope \& Hudson 1995; Kihlstrom, 1996; Pope et al, 1998). While there are methodological limitations and ambiguities about interpretation in all of these studies, as inevitably there are in research on real-life psychology, it is stretching credulity to claim that the collective evidence of these amounts to nothing.

Some of these studies show interesting correlations between the extent of forgetting and factors such as severity of violence in the abuse and closeness of the relationship to the abuser. Freyd (1996) has re-analysed data from these studies and found support for her 'betrayal trauma' hypothesis - that motivated amnesia results when a child experiences a conflict between awareness of the abuse and the need to preserve a bond to an important care-giver. An important point in Freyd's observations is that forgetting might not be a response to trauma per se, but to traumatic abuse in the context of intrapsychic and interpersonal conflict over awareness and remembering.

One interesting nine-year longitudinal study (Cameron, 1996) looked at 46 self-reported survivors of childhood sexual abuse, 25 of whom had forgotten their abuse for 15-54 years and 21 who had never forgotten. Most of those who recovered memories had done so between 1979 and 1985, a period when popular preoccupation with sexual abuse and survivor groups had not yet developed. Moreover, most of those who had forgotten $(73 \%)$ had recovered their first memories before entering therapy and $65 \%$ obtained external validation of their abuse (details are provided for some cases). Although both groups reported serious abuse, often by more than one perpetrator and lasting several years, the group with amnesia was more likely than the group without amnesia to report severe abuse involving violence and penetration and abuse by their mother or father; perhaps most crucially, the women in the amnesic group were three times more likely to report that in childhood there had not been an adult they could rely on. Both groups reported that their memories came to mind in response to certain cues, often exposure to knowledge of the abuse of someone close or to a similar setting or emotion; none of the women cited a book as a cue for memory recall. The women with amnesia tended to believe they had begun their recall of abuse at a time when they felt relatively safe. By contrast the women without amnesia tended to focus on their memories of abuse when they felt overwhelmed by life events. When the group without amnesia were asked why they thought they had never forgotten, their reasons included the following: an abuser who was not a parent was easier to avoid, perhaps then requiring less internal avoidance; in some sexually disturbed families the molestation was relatively undisguised rather than hidden or denied by the abuser; and some women deliberately remembered in order to learn from the experience.

One of the ways in which some commentators manage to dismiss evidence of motivated forgetting is by singling out a hypothetical subset of the phenomenon in question, calling this subset 'repression' or even 'robust repression', giving an idiosyncratic definition of repression and then declaring that there is no evidence for this phenomenon. It is implied that repression is a mysterious, counterintuitive or implausible mechanism. Sometimes there are even allusions to a 'theory of repression'. This is to confuse phenomena (forgetting) with a hypothesised mechanism ('repression'). As Brewin (1998) indicates, cognitive psychologists can consider a variety of processes that might be involved in failure to remember; he concludes: "Forgetting is not an all-or-none affair... There appears to be a continuum of difficulty in remembering".

In a much-quoted paper, Pope \& Hudson (1995) argue that a satisfactory study of repression must meet certain criteria. First, there must be confirmation that the traumatic events actually took place. Second, there must be evidence that the person actually developed psychogenic amnesia. This requirement rests upon further conditions:

"...one must first exclude cases in which victims simply tried not to think about the events, pretended that the events never occurred, or appeared to derive secondary gain by merely claiming to have amnesia (i.e. to avoid embarrassment)".

The problem with this argument is that trying not to think about painful events, or pretending they have not happened, is precisely how many survivors of sexual abuse describe the origins of their memory disturbance.

By attempting to define 'repression' as something other than this kind of process, Pope \& Hudson imply that repression is a mysterious mechanism which is beyond the reach of introspection or empathy. This is not how Freud (1915) originally described it. He wrote: "The essence of repression lies simply in turning something away, and keeping it at a distance from the conscious". This formulation does not appear to assume that repression is a completely unconscious process in origin, although the result might be that a piece of mental content has become unconscious. Freud gives an earlier account in his case study of Lucy R. who responds to his interpretation about her conflictual love for her employer by remarking: "I didn't know - or rather didn't want to know. I wanted to drive it out 
of my mind and not think about it again; and I believe latterly I have succeeded" (Freud \& Breuer, 18931895). In a footnote Freud comments: "I have never managed to give a better description than this of the strange state of mind in which one knows and does not know a thing at the same time". Erdelyi (1996) argues that the assumption that repression is meant to be an unconscious process is itself a kind of "grand Bartlett effect", a false belief produced by the repetition of a distorted message.

Another position taken by those who argue there is no evidence for motivated amnesia is to dismiss the many individual case reports as 'anecdotal' and therefore not of scientific value (Popeet al, 1998). To do so is to narrow the scope of available information unduly - a position which is at odds with the value placed on case studies in other areas of medicine. There are a number of such cases documented in the literature, sometimes termed functional retrograde amnesia or dissociative amnesia (Cohen, 1996; Schooler, 1996). One example is that of Ross Cheit, a Professor of Political Science at the University of Oregon. He suddenly remembered, from apparently a state of complete amnesia and with a great deal of affect, having been sexually abused by a church minister at a summer camp 24 years earlier; he has a tape-recorded confession from the abuser (Freyd, 1996). He and his psychologist colleague Jennifer Freyd, have set up a web site collecting examples of corroborated recovered memory (http:/ / www.brown.edu/Departments / Taubman_Center/Recovmem/Archive.html).

Studies of victims of severe trauma in Nazi concentration camps also provide relevant evidence. Krystal (1968), in his book Massive Psychic Trauma, found that disturbances of memory were "almost ubiquitous" among this group. Some of the traumatic memories had become hypermnesic, "occurring with such clarity and being so threatening that the patient cannot be sure that the old horrors have not in fact reappeared". However, Krystal goes on to say: "On the other hand, we also observed far-reaching memory defects with total or partial amnesia for various traumatic events, marked vagueness of the capacity to recollect, and the emergence of acute episodes of confusion and anxiety when urged to remember what the events were". The combination of amnesia and hypermnesia in concentration camp survivors was also noted by Wagenaar \& Groenweg (1990).

Further evidence comes from various experimental studies of directed forgetting (Cloitre, 1997) and hypnosis. Even some outspoken representatives of false memory syndrome will acknowledge this. For example, Kihlstrom (1996), a cognitive psychologist, drawing on his own work, states: "...studies of cued recall, recognition, and hypermnesia show that it is possible for people to remember at one point events that had been forgotten earlier...Similarly, research on hypnosis shows that people can block conscious access to particular memories and regain access sometime later; and that in the meantime, the unconscious memories can have implicit effects on the person's experience, thought and action...".

So there is certainly evidence for the possibility of motivated forgetting of childhood trauma. It is, as Brown et al (1998) state, a 'robust finding' across studies using very different methods and samples. This does not, however, constitute a justification for basing therapy on an attempt to recover memories of childhood trauma. It does mean that reports of partial or total amnesia for childhood abuse and subsequent recovery of memory for these events should not be dismissed out of hand.

\section{Context of memory retrieval}

In my own experience, and from what I have heard from other clinicians, psychotherapy is rarely the context for the initial recovery of memory of childhood sexual abuse. Rather, it is that patients seek therapy as a result of remembering trauma and experiencing distress about remembering. A very frequent context for remembering is when the patient has his or her own child, or when the child reaches an age at which the patient experienced abuse. Sometimes, it may be hearing about abuse in the media, or from a friend or relative, that triggers the recollection, or a chance re-encounter with the abuser. Not uncommonly, a patient will report that memories came back to awareness when they felt unusually safe, such as when in a supportive relationship. When asked about the previous state of not remembering, the patient may describe the process in terms of an active avoidance of thinking about the painful events, or of a wish to pretend the events had not happened.

Traumatic memories may emerge in partial and fragmented form. There may be errors in the interpretation of the memory fragments. For example, a patient reported that for many years she had been troubled by recurrent images of herself as a child with a man on top of her. At one point she had confronted her father, accusing him of abusing her. She had felt sure that he must have been the abuser because she hated him and reasoned that this was the reason for her hatred. He denied this and a family rift ensued. Some years later, her sister confided that it was not their father but their grandfather (now dead) who had abused both of 
them and that she had witnessed the grandfather abusing her sister. When asked why she had not revealed this information before, the sister explained that she had not wanted to think about the abuse and had been frightened of the grandfather when he was alive. All this happened before the patient had approached a psychotherapist or psychiatrist. The patient never recalled the childhood abuse explicitly. Did the abuse happen? She has only the sister's word for it, accompanied by her own image of the man on top of her. Did this involve a false memory? Actually, what the patient did was to take a context-free image and misinterpret its significance. She then falsely believed that her father had sexually abused her. However, if her sister's account is reliable, then her false accusation contained a core of displaced truth.

The recovery of memory of abuse may be highly traumatising and sometimes a patient's mental state may deteriorate markedly. Although memories which do emerge have to be dealt with, and the patient needs to be allowed to tell his or her story and be listened to with understanding, there is no doubt that dwelling on recollections of childhood trauma is not helpful; what is important is to examine and transform the meanings of the abuse, the distorted cognitions and the internal structures of self-other representations which have resulted from it.

\section{Traumatised states of mind}

Some commentators express incredulity at the idea that a person can avoid knowing about extensive abuse for long periods of time. The belief that this is implausible is understandable, perhaps inevitable, for those who have not spent large amounts of time with such psychiatric patients, often described as having a borderline personality disorder, whose background has been extremely disturbed. The memory disturbance of such patients has to be understood in the context of a much wider 'mutilation' (Mollon, 1996; 1998) of consciousness and cognition. These traumatised people do not live with normal states of mind. Instead, they tend to be hypervigilant, scanning for interpersonal danger, sometimes retreating into lethargic numbed states, often living on the edge of being overwhelmed with primitive affect, battling with destructive and threatening internal voices and in many cases experiencing rapid and unpredictable shifts from one state of mind to another. The last thing such patients wish to do is talk or think about childhood abuse, since to do so runs the risk of being overwhelmed. It would indeed be surprising if there were no disturbance of memory when so much else is abnormal in their cognition and awareness.

There is evidence that, in addition to psychodynamic processes which may inhibit memory for defensive purposes, psychological trauma impinges on brain function and structure in ways that disrupt memory (van der Kolk, 1996). Positron emission tomography scans, providing real-time displays of brain activity, demonstrate that during the experience of extreme trauma, a person may be in a state of wordless and incoherent terror (with increased activity in the amygdala, disruption of hippocampal functioning and closing down of Broca's area; Rauch et al, 1996). Such studies show disruption of the process of forming a coherent sensory experience which can be translated into a communicable verbal narrative.

Although this provides an account of disruption of memory, it does not explain recovery of coherent memory. Almost certainly any attempt to create a verbal narrative out of sensory motor fragments of traumatic memory would be prone to error. A confabulation might be generated which would appear to fit the fragments but could be quite different from the original events. Thus, those who were repeatedly traumatised in childhood may have disrupted memories, but may also be the most likely to generate confabulated memories.

The Harvard psychiatrist and trauma researcher, van der Kolk (1996), cautions about the uncertainty of recovered memory of trauma:

\footnotetext{
"The irony is that although the sensory perceptions reported in PTSD...may well reflect the actual imprints of sensations that were recorded at the time of the trauma, all narratives that weave sensory imprints into socially communicable stories are subject to condensation, embellishment, and contamination. Although trauma may leave an indelible imprint, once people start talking about these sensations and try to make meaning out of them, they are transcribed into ordinary memories - and, like all ordinary memories, they are prone to distortion."
}

This is a point on which there has been much misinformation and distorted argument. For example, the journalist Mark Pendergrast (1996) presents a mocking caricature of van der Kolk's work, alleging that he is "asserting the scientific validly of recovered memories" and attempting "to provide a scientific basis for massive repression/ dissociation". There is no evidence that van der Kolk has any such agenda - as the above quote makes clear. Pendergrast's attack is one of many examples in these disputes of the false attribution of beliefs and motives to those whose work is disapproved of. 


\section{Implicit memory}

Traumatic memory or memory of early experiences may not be recalled explicitly and consciously but may be represented as implicit or unconscious memory in the form of anxieties and behavioural enactments. Terr (1991) gives the example of a child who had been sexually molested by a babysitter in the first two years of life and could not, at age five years, remember or name the baby-sitter and denied any knowledge of being abused, but in his play enacted scenes that exactly replicated a pornographic film made by the baby-sitter. There are many vivid examples of implicit memory described in the literature (Terr, 1991; Mollon, 1998). The problem is that any attempt to reconstruct the original experience on the basis of an apparent implicit memory, in the absence of objective evidence, is liable to fall into error. Narrative fit is not the same as historical truth.

A person's deep schemas, or expectations, of self and other may be regarded as implicit memories, built up out of innumerable "repetitive interactions that have become generalised" (Stern, 1985). These are the focus of therapeutic work by both psychoanalysts and cognitive therapists. Transference itself is a form of implicit memory. Our memories, or memory-like fantasies, of interpersonal experiences of childhood will be congruent with the deep schemas - and may therefore have a metaphorical or thematic truth but to what extent we can ever recall the raw experience of childhood is open to question.

\section{Clinical implications}

In my view the most crucial implication of these controversies is that the psychiatrist or psychotherapist should tolerate uncertainty and ambiguity and avoid an illusion of knowing the truth of a person's childhood (Mollon, 1998). Dismissing and invalidating a patient's recovered memories should be avoided, as should inappropriate validation. In a therapeutic atmosphere that conveys respect for the patient's autonomy of mind, an anxious search for certainty, destructive of reflective thought, can be relinquished; the patient can experience the space to feel and think and explore without a premature reaching for a solution. An unbalanced focus on childhood trauma is likely to be unhelpful.
There is no reliable method of enhancing memory of childhood. Attempts to do so are likely to lead to confabulation. Nor are there any reliable means of distinguishing what is true from what is false in a memory of childhood without additional evidence (Brownet al, 1998).

Accurate information about memory, including areas of controversy, can be shared with the patient. Some readers may find useful the guidelines for patients regarding memory of childhood, which I use in my own work. These, as well as extensive guidelines for psychotherapists, are provided in Mollon (1998).

\section{Conclusion}

Psychiatrists and other mental health practitioners should do all they can to minimise the development of harmful false memories of childhood abuse. At the same time, it is important to be alert to ways in which the rhetoric of 'false memory syndrome', bolstered by the manner of its reporting in the media, itself becomes a damaging false narrative - one which is all the more persuasive for its repetition by figures of authority.

\section{Appendix}

\section{Guidelines for patients regarding memories of childhood events}

How accurate is memory? Is it like a videotape machine?

Memory is not like a videotape machine. It does not faithfully record, as on a film, everything that a person perceives. Memory is partly accurate and partly prone to a great many errors. Our memory for events may bear a rough resemblance to what actually happened, but may also include many inaccuracies. In some ways memory is like telling ourselves a story; each time we tell it, the story may be changed slightly. An adult's memory of childhood events may be particularly prone to error because of the length of time involved.

How can we be sure of the source of our memories?

Research suggests that under most circumstances people can successfully distinguish events that happened from events that were imagined. 
However, if there is extensive and repeated thought about an imagined event, the person can come to believe that the event actually happened. This kind of false memory could become highly detailed and vivid - indistinguishable, in how it feels, from a true memory. Some people who are very prone to suggestion and have unusually vivid imaginations may be particularly prone to false memories.

How reliable is the recall of early events?

Nothing can be recalled accurately from before the first birthday and little from before the second. Poor memory from before the fourth is normal.

\section{Is it possible to forget or 'repress' unpleasant} memories deliberately?

Forgetting certain kinds of painful experiences is often reported - but the precise process involved in the mind is unclear. There is currently much debate about whether this kind of forgetting of trauma takes place and, if so, how common it is. There is no firm research evidence that fully supports the idea of repression of memory. Apparent memories recovered later may in fact be false memories.

Is it possible to have false beliefs about the past?

There is a great deal of evidence that memories and beliefs about the past can be inaccurate in various ways. To what extent, and under what circumstances, it is possible for a person to arrive at completely false memories that have no basis in fact, is a matter of much current debate.

\section{Can hypnotic techniques help?}

Although there is a popular belief that hypnosis can help to elicit memories of the past, this is far from certain. What we do know with certainty is that hypnosis can create quite false memories which the person mistakenly believes to be true. Memories elicited through hypnosis are extremely unreliable. For this reason we do not recommend hypnosis as a means of recovering memories; to use hypnosis or similar techniques (such as guided imagery) for this purpose could be misleading and harmful.

\section{Can 'truth drugs' elicit lost memories?}

Drug-assisted abreactions (reliving of frightening events) have a long tradition in psychiatry and were used particularly after the Second World War to treat emotionally traumatised soldiers. However, as with hypnosis, there can be no certainty that events 'recovered' during an abreaction are literally true, especially when these concern childhood events of long ago.
Is it a good idea deliberately to search for memories of troubling events in childhood?

There can be two unfortunate consequences of deliberately searching for memories of traumatic events: (a) you may produce false memories; (b) if there are painful events which you have avoided thinking about, you may be overwhelmed by what you remember. It is best to allow your memory to respond naturally. It would be wrong to assume that any particular psychological problem necessarily stems from childhood trauma.

How should I deal with an apparent memory of a childhood event which suddenly emerges?

It is important not to jump to premature conclusions about an apparent memory of childhood. What has come into your mind may be literally true as a memory, or it may derive from fantasy or a dream or from some other source. In the absence of reliable additional evidence, it may be very difficult to know whether a memory is literally true or not. A false memory can appear as vivid, detailed and convincing as a true memory. It is the task of your doctor/psychotherapist/ psychologist/counsellor to help you think about these possibilities and for you to arrive at your own conclusions in due course. It would be most unwise for you to take any course of action in relation to particular individuals solely on the basis of a 'memory' recovered during therapy.

We hope you find these guidelines informative and that they help to avoid misunderstandings regarding very complex processes in the mind. There is a need for great caution in this area because of the harm that false memories can cause to relationships within families.

\section{References}

Bartlett, F. C. (1995) Remembering. A Study in Experimental and Social Psychology. Cambridge: Cambridge University Press.

Brandon, S., Boakes, J., Glaser, D., et al (1998) Recovered memories of childhood sexual abuse. Implications for clinical practice. British Journal of Psychiatry, 172, 296-307.

Brewin, C. R. (1998) Commentary: Questionable validity of 'dissociative amnesia' in trauma victims. British Journal of Psychiatry, 172, 216-217.

British Psychological Society (1995) Recovered Memories: The Report of the Working Party of the British Psychological Society. Leicester: British Psychological Society.

Brown, D., Scheflin, A. W. \& Hammond, D. C. (1998) Memory, Trauma Treatment and the Law. New York: Norton.

Cameron, C. (1996) Comparing amnesic and non-amnesic survivors of childhood sexual abuse: a longitudinal study. In The Recovered Memory/False Memory Debate (eds K. Pezdek \& W. P. Banks), pp. 41-68. London. Academic Press.

Cloitre, M. (1997) Consciousness and unconscious memory A model of functional amnesia. In Cognitive Science and 
the Unconscious (ed. D. Stein). Washington, DC: American Psychiatric Press.

Cohen, N. J. (1996) Functional retrograde amnesia as a model of amnesia for childhood sexual abuse. In The Recovered Memory/False Memory Debate (eds K. Pezdek \& W. P. Banks), pp. 81-95. London: Academic Press.

Erdelyi, M. H. (1996) The Recovery of Unconscious Memories. Hypermnesia and Reminiscence. Chicago, IL: University of Chicago Press.

Freud, S. (1915) Repression. Reprinted (1953-1974) in The Standard Edition of the Complete Psychological Works of Sigmund Freud (trans. and ed. J. Strachey), vol. 14. London: Hogarth Press.

Freud, S. \& Breuer, J. (1893-1895) Studies on Hysteria. Reprinted (1953-1974) in The Standard Edition of the Complete Psychological Works of Sigmund Freud (trans. and ed. J. Strachey), vol. 14. London: Hogarth Press.

Freyd, J. J. (1996) Betrayal Trauma. The Logic of Forgetting Childhood Abuse. Cambridge, MA: Harvard University Press.

Hovdestad, W. E. \& Kristiansen, C. M. (1996) A field study of 'false memory syndrome': Construct validity and incidence. Journal of Psychiatry and Law, 24, 299-338.

Kihlstrom, J. F. (1996) The trauma-memory argument and recovered memory therapy. In The Recovered Memory/False Memory Debate (eds K. Pezdek \& W. P. Banks), pp. 297311. London: Academic Press.

Krystal, H. (1968) Massive Psychic Trauma. New York: International Universities Press.

Loftus, E. F., Garry, M. \& Feldman, J. (1994) Forgetting sexual trauma. What does it mean when $38 \%$ forget? Journal of Consulting and Clinical Psychology, 62, 1177-1181.

Mollon, P. (1996) Multiple Selves, Multiple Voices. Working with Trauma, Violation and Dissociation. Chichester: Wiley.

- (1998) Remembering Trauma. A Psychotherapist's Guide to Memory and Illusion. Chichester: Wiley.

Pendergrast, M. (1996) Victims of Memory. Glasgow: Harper Collins.

Pope, H. G. \& Hudson, J. I. (1995) Can memories of childhood sexual abuse be repressed? Psychological Medicine, 25, 121-126.

- - - Bodkin, J. A., et al (1998) Questionable validity of 'dissociative amnesia' in trauma victims. Evidence for prospective studies. British Journal of Psychiatry, 172, 210-215.

Rauch, S., van der Kolk, B. A., Fisler, R., et al (1996) A symptom provocation study of post-traumatic stress disorder using positron emission tomography and script-driven imagery. Archives of General Psychiatry, 53, 380-387.

Schooler, J. W. (1996) Seeking the core: The issues and evidence surrounding recovered accounts of sexual trauma. In The Recovered Memory/False Memory Debate (eds K. Pezdek \& W. P. Banks), pp. 279-296. London: Academic Press.

Stern, D. (1985) The Interpersonal World of the Infant. New York: Basic Books.

Terr, L. (1991) Childhood traumas: an outline and overview. American Journal of Psychiatry, 148, 10-20.

van der Kolk, B. A. (1996) Trauma and memory. In Traumatic Stress (eds B. A. van der Kolk, A. C. McFarlane, \& L. Weisaaeth), pp. 279-302. New York: Guilford.

Wagenaar, W. A. \& Groeneweg, J. (1990) The memory of concentration camp survivors. Applied Cognitive Psychology, 4, 77-87.

\section{Multiple choice questions}

1. Recovered memory therapy is:

a a new development within psychoanalysis

b now widely practised in the UK

c the treatment of choice for childhood sexual abuse

d only harmful if carried out by poorly trained practitioners

e a term invented by the false memory societies.

2. Memory is best regarded as being:
a like a videorecording
b like a computer file
c like recounting an anecdote of the past
d like a photograph
e like a dream, having little literal truth.

3. Repression (as described by Freud) is:

a an entirely unconscious mechanism which blocks memory

b a mechanism which selectively targets memories of sexual trauma

c a hypothesised mechanism for which there is no objective evidence

$d$ the cause of eating disorders in later life

e a process of turning away from thoughts that are painful.

4. Evidence suggesting motivated forgetting of childhood trauma is:

a completely lacking

b restricted to four studies

c is provided in over 30 studies

$\mathrm{d}$ is not supported by any corroborated individual case studies

e restricted to anecdotes in popular books.

5. When faced with a patient who reports remembering childhood abuse which had previously been forgotten, the psychiatrist should:

a accept that this is an essentially true recollection

b tell the patient that he or she is suffering from false memory syndrome

c contact the alleged abusers for their opinion

$\mathrm{d}$ ignore what the patient has said about abuse so as to extinguish false memory behaviour

e listen carefully but convey neither validation not dismissal of the report of abuse.

\section{MCQ answers}

$\begin{array}{llllllll}\text { 1 } & & \text { 2 } & 3 & 4 & 5 \\ \text { a F } & \text { a F } & \text { a F } & \text { a F } & \text { a F } \\ \text { b F } & \text { b F } & \text { b F } & \text { b F } & \text { b F } \\ \text { c F } & \text { c T } & \text { c F } & \text { c T } & \text { c F } \\ \text { d F } & \text { d F } & \text { d F } & \text { d F } & \text { d F } \\ \text { e T } & \text { e F } & \text { e T } & \text { e F } & \text { e T }\end{array}$

